\title{
A JUSTIÇA RESTAURATIVA: BREVE ANÁLISE DE VIVÊNCIAS SOB O OLHAR DA EXTENSÃO UNIVERSITÁRIA
}

\author{
Daniel Félix Gondim Barbosa ${ }^{1}$ \\ Yuri Silva Lima ${ }^{2}$
}

Logo no início do ano de 2019, as universidades públicas sofreram ataques abertos, acendendo na população o sentimento de aversão às atividades desenvolvidas no mundo acadêmico. Versões inadequadas da realidade têm manchado o papel social das referidas instituições e cabe aos estudantes e professores mostrarem o que, de fato, acontece dentro dos muros de uma Instituição Pública de Ensino Superior. Sair do espaço teórico e viver a prática deve ser o primeiro passo para desconstruir as alegações infundadas que fragilizam a imagem universitária. É por isso que grupos de extensão corroboram com a elevação dos índices institucionais. Urge a necessidade de restaurar os vínculos comunitários com a academia. A horizontalidade e o diálogo são os princípios deste mundo novo que se descobre e constrói com a participação popular e estudantil.

A universidade pública é constituída pelo tripé ensino, pesquisa e extensão. Por esta razão, é importante que dentro da academia se engendrem ações que visem contribuir para o desenvolvimento social da comunidade na qual está inserida. Não por menos, o projeto de extensão Direitos Humanos na Prática-ou, simplesmente, DH na Prática - visa contribuir com o corpo social da cidade de Mossoró, proporcionando às localidades, especificamente às instituições que trabalham com sujeitos caracterizados pela hipossuficiência e marginalização, conhecimentos relacionados à cidadania e à proteção de direitos. Trata-se, portanto, de um indispensável elo na concretização do terceiro sustentáculo constitutivo da Instituição.

O projeto nasceu no seio da Universidade Federal Rural do Semi-Árido (UFERSA), objetivando atender demandas que estivessem relacionadas com a prática dos direitos humanos. Primordialmente, a atuação se dava no âmbito do Centro de Educação (CEDUC), hoje Centro de Atendimento Socioeducativo (CASE), assegurando aos adolescentes o conhecimento processual que lhes é previsto na Lei 8.069/90. Contudo, nas discussões suscitadas nos encontros semanais do projeto, constatou-se a necessidade de ampliar o leque de atuações, abraçando novos campos para uma atividade direta na prestação dos direitos intrínsecos à pessoa humana. Dessa forma, o Centro de Referência de Assistência Social (CRAS) de determinado bairro ${ }^{3}$ da cidade foi escolhido para a atuação do programa. Os outros segmentos, Escola e Unidade Básica de Saúde

\footnotetext{
${ }^{1}$ Estudante do curso de Direito da Universidade Federal Rural do Semi-Árido. Membro extensionista do grupo Direitos Humanos na Prática. E-mail: danielfelix324@gmail.com.

${ }^{2}$ Estudante do curso de Direito da Universidade do Estado do Rio Grande do Norte. Membro extensionista do grupo Direitos Humanos na Prática. E-mail: yurilimabio@gmail.com.

${ }^{3}$ Por motivo de respeito às vivências compartilhadas com o grupo DH na Prática e em nome do princípio do sigilo adotado na metodologia restaurativa, o nome do bairro e das instituições trabalhadas não serão divulgados.
} 
(UBS) da comunidade, foram consequência do primeiro, vistos como correlacionados ao CRAS, uma vez que o público alvo é constituído de pessoas da referida localidade e sujeitos conhecedores das dificuldades que a população enfrenta.

Os segmentos selecionados para o desenvolvimento das atividades do projeto de extensão possuem uma ligação estreita quanto à prestação da assistência social ou promoção da saúde. Destarte, ambos “deverão favorecer envolvimento e a participação de todas as pessoas, as organizações da sociedade civil, as associações de bairros, etc.” (SODRÉ, 2014, p.74), dentro de cada especificidade. É indispensável, por conseguinte, o estabelecimento de um diálogo acolhedor, organizado e transformador, seja entre os membros das equipes técnicas ou destes com os indivíduos atendidos.

Isto posto, a metodologia das práticas restaurativas não se delimita à pré-existência de um conflito. Doutra forma, a relação restaurativa "centra-se no agir comunicativo dos atores sociais" (PORTO, 2008, p.15). Nessa perspectiva, almejando sempre relações horizontalizadas dialógicas, fragilidades nas instituições e relações podem ser trazidas ao centro da conversa e observadas sob óticas diferentes. De fato, este não é um trabalho massificado e padronizado, visto que cada singularidade é uma perspectiva a ser considerada, então diversos obstáculos precisam ser superados, estando no diálogo circular os elementos que podem romper paradigmas, estabelecer e renovar relações.

Feitas estas considerações, importa salientar que o presente trabalho pretende apontar o caráter diferencial que o projeto traz para a consolidação da universidade, sobretudo a pública, e dos cursos de Psicologia, Serviço Social, Pedagogia, e Direito, dentro da comunidade mossoroense, levando para bairros o olhar crítico e empoderado que são caros à efetivação da cidadania. Assim, a metodologia da Justiça Restaurativa (JR) foi de grande importância para a dinâmica de conhecimento e vivência nas instituições. Por atribuir aos convívios práticas horizontais, o encontro dos extensionistas com estudantes, funcionários e população em geral, era/é recheada de histórias que possibilitam a descoberta de fragilidades que, sob o enfoque restaurativo, podem ser solucionadas mediante diálogos. No entanto, não se exclui deste trabalho os obstáculos que precisaram ser superados. Portanto, como será possível depreender, os princípios norteadores da JR (alteridade, escuta, respeito e compreensão, por exemplo), foram cruciais para o bom desenvolvimento da proposta de intervenção extensionista nos segmentos que se verá, objetivando, afinal, a supressão ou minimização das intempéries que nascem dos conflitos potencializados.

A socialização humana integra um processo lento e complexo que possui a experiência como delimitador daquilo que convém ao bom convívio humano. Não por menos, as visões de punição adotadas pelas Nações durante os séculos têm se modificado. Enquanto as primeiras prisões eram concebidas como locais de espera para a possível condenação do acusado, que normalmente se concretizava com a morte, as atuais tentam implementar a ressocialização do agressor por meio do sistema retributivo, no qual a pena nada mais é do que a representação real do jus puniendi, sem suscitar na vítima graus de reparação que a faça sentir contemplada pela justiça. A Justiça Restaurativa (JR) tem sido a experiência com melhores resultados.

A JR é um meio de resolução de conflitos cujo o objetivo maior está na restauração do indivíduo e, 
consequentemente, dos vínculos. Ela compreende que o corpo social é uma teia que molda todos aqueles que a constroem. Assim sendo, busca, através da voluntariedade da vítima, agressor e, sempre que possível, da comunidade, desenvolver formas de solução para questões advindas das dissensões entre as partes. Logo, existem metodologias e princípios norteadores que favorecem sua aplicação em diversas situações.

O círculo é a expressão geométrica que apresenta perfeita sintonia. Não há arestas. É ligado continuamente, ou seja, não existem quebras. Consequentemente, é a melhor forma de dispor as pessoas para o desenvolvimento do diálogo. Essa é a configuração adotada na JR e isso se dá pela possibilidade de integração entre os partícipes, pela horizontalidade, pelo olhar e, sobretudo, pelo sentimento despertado que possibilita o perdão e a reconstrução de vínculos. Não é a simples distribuição dos pares, como ocorre na justiça convencional, e as pretensões do ofendido não são delegadas ao Estado, que assumiria o seu lugar. Pretende-se, na verdade, desenvolver consciência e competência emocional, além da prática da atenção plena, para que, assim, o ambiente seja um lugar seguro para compartilhar vivências. Só desta forma existirá a possibilidade de remediar e evitar que novos conflitos surjam na comunidade.

Entretanto, é mister destacar que a JR não trata necessariamente de perdão e conciliação, mas eles podem vir a ser resultados de práticas restaurativas. Também não é um substituto ao sistema positivado. Ora, a punição é necessária em diversos casos. Aquela modalidade, no entanto, vem assegurar que a vítima seja amparada e que o ofensor repare o dano sem esvaziar o rol intrínseco dos direitos humanos. Estes apontamentos, feitos por Howard Zehr, são importantíssimos para que se compreenda os princípios que impulsionam o diálogo dentro do círculo. Essa é apenas uma forma de utilizar a Justiça Restaurativa. Todavia, ela pode e é utilizada em outros ambientes sociais pelo seu papel primordial de fomentar o compartilhamento de sensações e histórias. Segundo Zehr (2008, p. 174), a lente restaurativa “identifica as pessoas como vítimas e reconhece a centralidade das dimensões interpessoais. As ofensas são definidas como danos pessoas e como relacionamentos interpessoais". O ser humano, afinal, é uma equalização de diferentes emoções e, quanto mais sente, mais se identifica. É o que transfere às pessoas aquilo que marca a diferenciação real entre todo o reino animal: a humanidade.

Dessa forma, o papel restaurativo é importante para a elaboração de atividades dentro dos segmentos de base que serão apresentados. O maior problema para adentrar nestas comunidades e conhecer suas histórias é a abertura para a conversa. Isto contribui para o afastamento da comunidade da totalidade municipal. É perceptível o sentimento de não pertencimento à cidade onde moram. Muitos utilizam, inclusive, a expressão "ir à Mossoró" quando pretendem sair do bairro onde residem. Isto ocorre porque “muitas pessoas na nossa sociedade carecem de um sentido de poder pessoal” (ZEHR, 2008, p. 53). Portanto, como se verá adiante, a metodologia da Justiça Restaurativa possibilita o desenvolvimento de vínculos que resultam na construção de mudanças estruturais e de afinidade com o ambiente onde se vive.

As instituições de assistência social e de saúde neste trabalho analisadas estão situadas em um bairro de uma zona não-central no município de Mossoró, na unidade federativa do Rio Grande do Norte. Nessa localidade, as instituições funcionam ativamente, mesmo que em condições peculiares, tais como espaços 
pequenos para realização de atividades ou localidades temporárias, utilizados por um grande lapso temporal devido a reformas no estabelecimento oficial. Logo, um primeiro óbice a ser ultrapassado são as tratativas especiais e estruturais para o desenvolvimento das ações rotineiras e, também, dos próprios círculos restaurativos.

Ademais, compreendendo a importância da atividade de extensão, esta deve estar, além de fundamentada teoricamente, programada dentro de um planejamento que compatibilize e possibilite a realização harmônica entre as instituições, fitando alcançar de forma satisfatória o resultado esperado nos períodos de estruturação das ações. Assim sendo, outro desafio a ser superado consta na verificação da disponibilidade de horário de todos os envolvidos - dos diferentes setores e escalas -, para a realização de uma dinâmica circular integrativa e com maior alcance de interessados, conforme o planejamento preliminarmente construído.

Prosseguindo, dois outros fatores estão intimamente entrelaçados, e são: o receio em "abrir as portas das instituições" quanto à sua organização e estratégias de funcionamento internas, bem como à sua falta de informações sobre o funcionamento, objetivos, definição e formas de aplicação da metodologia circular da Justiça Restaurativa. Desse modo, em todas as instituições foram realizadas intervenções introdutórias sobre o objetivo do projeto de extensão, sua finalidade e sobre a Justiça Restaurativa, para que, após longas argumentações, florescesse a motivação das instituições a aceitarem voluntariamente a execução das ações.

Todavia, estando os desafios superados - principalmente após a apresentação da metodologia de atuação, da repercussão de casos práticos de outros círculos e da abertura pelas instituições -, ambas as analisadas se mostraram interessadas em contribuir com as ações. Estas poderiam repercutir positivamente no melhor funcionamento da relação entre as equipes, os labutadores das unidades e os usuários dos serviços, construindo uma teia colaborativa, ou, numa melhor analogia, um enorme círculo harmônico de prestação social e de saúde.

Como consequência do contato com o CRAS e UBS, a Escola Municipal não apresentou problemáticas diferentes daqueles primeiros. Isto, de fato, corrobora com a premissa apresentada: os seres humanos fazem parte de uma teia social. Destarte, a primeira preocupação, ao visitar a unidade escolar, foi visualizar o planejamento de um círculo que facilitasse o diálogo. Assim, optou-se pela abordagem sob a ótica dos discentes. Inúmeras foram as razões para tanto: a) os alunos são a razão de ser da instituição; b) é preciso, para compreender o ambiente escolar, conhecer o público alvo; e c) depreende-se que os adolescentes presentes no Centro de Referência de Assistência Social são os mesmos que estão na escola do bairro. Por conta disto, e almejando verificar se as dificuldades seriam as mesmas, é que os estudantes foram cruciais para esta vivência.

O primeiro empecilho detectado foi a falta de coalizão das forças representativas da escola, tanto ao nível pedagógico, quanto estudantil. Observou-se que não existia diálogo entre docentes e discentes, uma vez que, ao repassar o convite feito pelo grupo de extensão, a motivação para a participação do momento restaurativo se deu por falha na comunicação, inserindo nos alunos a falsa percepção de que a ação seria outra 
e não aquela que estaria por acontecer. Outrossim, como segunda problemática, a organização estudantil se apresentou precária e a força para o diálogo com os discentes, fragilizada. Por fim, a instituição também sinalizou, involuntariamente, ruídos na vivência entre os profissionais, o que, por sua vez, resulta na desestruturação funcional da escola.

Levando em conta a razão de ser da extensão universitária, estes apontamentos foram levados para os encontros semanais do grupo de extensão, o que, por sua vez, resultou na elaboração de um círculo de diálogo com os discentes da Escola. O propósito deste momento foi construir vínculos entre os adolescentes da Instituição de Ensino e os extensionistas do grupo DH na Prática. Ademais, pretendia-se desenvolver e fortalecer os laços de amizade baseados no respeito. Assim, no dia 09 de outubro de 2019 os participantes se reuniram para a realização do Círculo Restaurativo. A excelência do momento pôde ser sentida no compartilhamento de informações sobre as expectativas dos integrantes, das suas experiências sociais, das dificuldades de morar em um bairro afastado do centro urbano de Mossoró e dos obstáculos que impedem a efetiva representação estudantil.

Com o material coletado, as próximas atividades a serem aplicadas na Entidade Educacional tentarão atender o corpo dos dissensos. Nas últimas reuniões do projeto de extensão do ano de 2019 já se vislumbrava a possibilidade de fomentar a realização de uma representação estudantil que conte com efetiva pauta voltada diretamente para os interesses do alunado. É de interesse dos extensionistas disseminar o sentimento de cidadania, imbuindo nestas pessoas e em suas diversas esferas a essência do ser-cidadão. Com este sentimento, em 2018 o projeto de extensão e o Centro de Mediação e Práticas Restaurativas (CMPR), desenvolvido no seio do projeto de extensão Centro de Referência em Direitos Humanos (CRDH), lançaram uma cartilha ${ }^{4}$ que pretende disseminar o conhecimento das atividades e metodologias restaurativas, mostrando, afinal, o resultado deste trabalho desenvolvido na Universidade Pública com o empenho dos estudantes e professores.

Como grupo predominantemente formado por bacharelandos em Direito, é importante levar para a comunidade a materialização de direitos que fundam o sistema constitucional brasileiro e, consequentemente, o povo pátrio. Nossa Constituição tem sofrido violações que a transformam em uma norma simbólica, própria para atender aos interesses de atores que não aqueles que, devidamente, deveriam ser prioridade. Não é novidade que garantias são vilipendiadas cotidianamente sem nos darmos conta de quem ou o que as rouba de nós. A troca de experiências entre a população civil e os universitários traz realização e humanidade, principalmente para os profissionais que se almeja formar no Direito. Aplicar leis e estatutos não deve fugir da análise material. Para que o ordenamento jurídico tenha validade entre seus destinatários, é preciso que aqueles que se sujeitam a ele o respeitem, mas também o entendam, para que, só assim, possa esse ter eficácia, eficiência e efetividade. Analogicamente, a universidade pública brasileira também deve funcionar nesse diapasão, voltando-se para a comunidade que serve.

\footnotetext{
${ }^{4}$ Cf. OLIVEIRA, Ramon Rebouças Nolasco de et al. Justiça Restaurativa nas escolas. Organizador: Ramon Rebouças Nolasco de Oliveira. Mossoró: EdUFERSA, 2018.
} 


\section{REFERÊNCIAS BIBLIOGRÁFICAS}

OLIVEIRA, Ramon Rebouças Nolasco de et al. Justiça Restaurativa nas escolas. Organizador: Ramon Rebouças Nolasco de Oliveira. Mossoró: EdUFERSA, 2018.

PORTO, Roseane Teresinha Carvalho. A Justiça Restaurativa e as políticas públicas de atendimento a criança e ao adolescente no Brasil: uma análise a partir da experiência da $3^{\circ}$ Vara Regional da Infância e da Juventude de Porto Alegre. Dissertação (Mestrado em Direitos Sociais e Políticas Públicas). Universidade de Santa Cruz do Sul, Santa Crus do Sul, 2008. Disponível em: $<$ http://www.dominiopublico.gov.br/download/teste/arqs/cp060751.pdf>. Acesso em: 05 nov. 2019.

SODRÉ, Francis. O serviço social entre a prevenção e a promoção da saúde: tradução, vínculo e acolhimento. Serv. Soc. Soc. São Paulo, n. 117, jan/mar, 2014. Disponível em: $<$ htttp://www.scielo.br/pdf/sssoc/n117/05.pdf >. Acesso em: 05 nov. 2019.

ZEHR, Howard. Trocando as lentes: um novo foco sobre o crime e a justiça. Tradução de Tônia Van Acker. São Paulo: Palas Athena, 2008. 